\title{
Phenetic Variation and Preliminary Phytochemical Screening of Piper Species in Sri Lanka
}

\author{
S.P.N.C. Jayarathna ${ }^{1}$, S.P. Senanayake ${ }^{1}$, S. Rajapakse $^{2}$ and L.R. Jayasekera ${ }^{1}$ \\ Received: $11^{\text {th }}$ November 2015 / Accepted : $4^{\text {th }}$ March 2016
}

\begin{abstract}
The genus Piper has high commercial importance as it contains cultivated crops (black pepper and betel) and medicinal plants that are mostly used in traditional medicine. In Sri Lanka the genus Piper is represented by ten species including five wild species. It is necessary to examine their chemical composition and morphology as they have received little attention for utilizing their valuable traits for crop improvement. Piper nigrum L., P. betle L., P. longum L., P. chuvya (Miq.) C. DC., P. siriboa L., P. sylvestre Lam., P. zeylanicum Miq. P. walkeri Miq were subjected to morphological and phytochemical study using the specimens collected from natural habitats and from the cultivations. The air dried and powdered leaves were used for qualitative phytochemical screening. Qualitative phytochemical screening was carried out to identify the different chemical compounds in petroleum ether, chloroform, methanol and water. The study confirmed the presence of tannins, flavonoids, terpenoids, glycosides, alkaloids and phenolic compounds. Anatomical studies were carried out by obtaining leaf epidermal peels and cross sections. Thirteen morphological and anatomical characters were subjected to cluster analysis using PAST software to infer their relationships. According to the phenogram (Single linkage, Euclidean distance) the taxa were divided into two main clusters; P. longum, P. zeylanicum, P. sylvestre, P. nigrum and P. walkeri formed one cluster whereas $P$. chuvya, $P$. betle, $P$. siriboa formed the other cluster sharing similarities. P. betle varieties were clustered together with P. siriboa and P. chuvya within the second cluster. Therefore, potential strengths in disease resistance of P. siriboa and P. chuvya can be used to develop improved varieties of betel to minimize economic losses due to epidemics in cultivations.
\end{abstract}

Keywords: Piper, phenetic variation, phytochemical screening

\section{INTRODUCTION}

The genus Piper, which belongs to the family Piperaceae is the largest in the family. The family consist of more than 1000 species, occurs throughout the tropical and subtropical regions (Parthasarathy et al., 2006). People throughout the tropics use Piper for many purposes, such as food, ornamentals, spices, perfumes, oils, insecticides, and many medicines. The genus Piper is widely distributed in the understory and secondary vegetation of tropical forests, particularly in Asia and Neotropics. They are characterized by a shrubby to sub-tree habit, thickened nodes and spicate inflorescences with minute bracteates flowers (Wadt et al., 2004).

In Sri Lanka the genus Piper is represented by ten species (Table 01). The main cultivated crops in the genus include Piper nigrum L. and $P$. betle L. Three species are endemic to the country; P. zeylanicum Miq. P. trineuron Miq. and $P$. walkeri Miq., whereas five species are considered as introduced. $P$. walkeri Miq. and $P$. trineuron Miq. are found to be recorded in few localities of the country and P. hymenophyllum 
Miq. is considered as an extremely rare species. $P$. sylvestre Lam. is the most widespread Piper species in the country. P. siriboa L., P. longum L. and P. chuvya (Miq.) C. DC. are commonly used in traditional medicines (Huber, 1987; Edirisinghe, 2009; Senaratna, 2001; Liyanage \& Senanayake, 2010).

People have used genetic material from crop wild relatives to improve the quality and yield of crops for thousands of years. Natural crosses between crops and their wild relatives have occurred since the beginnings of agriculture. Recently plant breeders have started to utilize the genes of crop wild relatives to improve a wide range of crops. Further, crop wild relatives are essential components of natural ecosystems and agricultural eco-systems. Therefore they are vital for maintaining ecosystem health. In order to improve agricultural production, increase food security, and maintain a healthy environment, conservation and sustainable use of crop wild relatives is very important. Although Sri Lanka is an important centre for crop wild relative diversity, these populations are under threat due to habitat destruction and other human activities (Department of Agriculture, Government of Sri Lanka, 2006).

Among wild species morphological variation is usually very wide indicating adaptability to different environmental conditions hence, it is important to explore the inherent variation in morphological characters. Foliar morphological features such as trichomes and hairs are very diverse in their features and functions and have been interpreted as play defensive role in plants. They provide protection from various external factors: herbivores and pathogens, extensive light, extreme temperatures, excessive water loss, allelopathy against competitor plants, etc. (Werker, 2000).

Phytochemicals are plant secondary metabolites with stable chemical characters used for the determination of relationships of different taxa. Main groups of secondary metabolites in plants are terpenoids, phenolics, and alkaloids. Piper species are rich in variety of phytochemicals like polyphenols, alkaloids, steroids, saponins and tannins hence they possess wide array of activities like antibacterial, antioxidative and antihaemolytic, insecticidal activities (Shun et al., 2007; Chakraborty and Shah, 2011). Due to their biological activities, plant secondary metabolites have been used for centuries in traditional medicine (Bourgaud et al., 2001).

This study aimed to reveal the interspecific relationships of selected Piper species based on the variation in qualitative phytochemical screening and phenetic approach.

Table 01: Botanical and vernacular names of Piper species in Sri Lanka

\begin{tabular}{ll}
\hline \multicolumn{1}{c}{ Botanical name } & \multicolumn{1}{c}{ Vernacular name (Sinhala) } \\
\hline Piper nigrum L. & Gammiris-wel \\
P. betle L. & Bulat, Bulat-wel \\
P. longum L. & Tippili \\
P. chuvya (Miq.) C. DC. & Seewiya-wel, Mala bulath \\
P. siriboa L. & Rata bulat wel, Rata karal, Siribo \\
P. sylvestre Lam. & Wal gammiris-wel \\
P. zeylanicum Miq. & - \\
P. walkeri Miq. & - \\
P. trineuron Miq. & - \\
P. hymenophyllum Miq. & - \\
\hline
\end{tabular}

Sources: Huber, 1987; Senaratne, 2001 


\section{MATERIALS AND METHODS}

\section{Phenetic Variation}

Plant specimens of Piper nigrum, P. betle, $P$. longum, $P$. chuvya, $P$. siriboa, $P$. sylvestre, $P$. zeylanicum and $P$. walkeri were collected from natural habitats and cultivations. Two varieties of $P$. longum and three varieties of $P$. betle (Ratadalu, Maneru and Nagawalli) were used for the study. Morphological characters of leaves, the shape of the spadices were observed, internodal distance, petiole lengths were measured using a measuring tape.

A mature leaf was used for the preparation of epidermal peels for the observations. Several leaf pieces obtained from close to the mid rib were excised and were immersed in two consecutive treatments of $5 \% \mathrm{KOH}(24-48$ hours per treatment), then rinsed in deionized water and treated for a few minutes in glacial acetic acid and cleared in bleach (6\% Sodium hypochlorite). Following the clearing, samples were dehydrated in an ethanol series and stained in safranin for 30 seconds. After that the samples were mounted onto microscopic slides. Mesophyll tissues were removed under a dissecting microscopeleaving only the epidermis to be mounted (Carpenter, 2006). Both adaxial and abaxial epidermal specimens were prepared for each leaf sample. Cross sections were taken from leaves and stems. Specimens were examined under Labomed LX 400 trinocular research microscope equipped with Labomed iVu 3000 camera and photomicrographs were prepared.

Morphological features and anatomical features (Table 02.) of the leaves were used to construct the phenogram by PAST (Paleontological STatistics) software to interpret phenetic relationships of the taxa. Principal component analysis (PCA) was carried out using the same software.

\section{Qualitative Phytochemical Screening}

Leaves were thoroughly washed and air dried, powdered using a grinder and the powder (20 g) was extracted sequentially with petroleum ether $(50 \mathrm{ml})$, chloroform $(50 \mathrm{ml})$, ethyl acetate $(50 \mathrm{ml})$ and methanol $(50 \mathrm{ml})$ respectively by keeping overnight in a shaker and then the extracts were filtered.

Water extracts were obtained by boiling ( $20 \mathrm{~g}$ ) of powdered leaf materials of each specimen in $50 \mathrm{ml}$ of distilled water and were filtered. All the extracts were subjected to preliminary phytochemical screening following standard procedures (Harborne, 1998: Khandelwal, 2008).

\section{Table 02: Characters used for PCA}

\begin{tabular}{cl}
\hline Symbol & \multicolumn{1}{c}{ Character } \\
\hline A & Leaf colour \\
B & Leaf length $(\mathrm{cm})$ \\
C & Leaf width $(\mathrm{cm})$ \\
D & Internodal distance $(\mathrm{cm})$ \\
E & Petiole length $(\mathrm{cm})$ \\
F & Leaf lamina shape \\
G & Shape of the leaf base \\
H & Symmetry of the base \\
I & Shape of the leaf apex \\
J & Leaf area $\left(\mathrm{cm}^{2}\right)$ \\
K & Presence of stomata on adaxial epidermis \\
L & Presence of non glandular trichomes on leaves \\
M & Presence of fleshy spadix with concrescent berries \\
\hline
\end{tabular}


i) Tannins

To $2-3 \mathrm{ml}$ of extract $0.1 \% \mathrm{FeCl}_{3}$ was added and observed for brownish green or a blue black colouration which showed the presence of tannins.

ii) Saponins

The extract was shaken vigorously to obtain a stable persistent froth. The frothing is then mixed with 3 drops of olive oil and for the formation of emulsion which indicates the presence of saponins.

iii)Flavonoids

(a) A few drops of $1 \% \mathrm{NH}_{3}$ solution was added to the extract of each plant sample in a test tube. A yellow coloration is observed if flavonoids compound were present.

(b)Alkaline reagent test

Test solution when treated with sodium hydroxide solution shows increase in the intensity of yellow colour, which becomes colourless on addition of few drops of dilute acid.

iv) Terpenoids

Extract of each plant sample $(5 \mathrm{ml})$ was mixed with $2 \mathrm{ml}$ of $\mathrm{CHCl}_{3}$ in a test tube $3 \mathrm{ml}$ of concentrated $\mathrm{H}_{2} \mathrm{SO}_{4}$ was carefully added to the mixture to form a layer. An interface with a reddish brown coloration is formed if terpenoids constituent is present.

v) Test for cardiac glycosides

Concentrated $\mathrm{H}_{2} \mathrm{SO}_{4}(1 \mathrm{ml})$ is prepared in test tube $5 \mathrm{ml}$ of extract from each plant sample was mixed with $2 \mathrm{ml}$ of glacial $\mathrm{CH}_{3} \mathrm{CO}_{2} \mathrm{H}$ containing 1 drop of $\mathrm{FeCl}_{3}$. The above mixture was carefully added to $1 \mathrm{ml}$ of concentrated $\mathrm{H}_{2} \mathrm{SO}_{4}$ so that the concentrated $\mathrm{H}_{2} \mathrm{SO}_{4}$ was underneath the mixture. If cardiac glycoside was present in the sample, a brown ring will appear indicating the presence of the cardiac glycoside constituent.
vi)Alkaloids

Mayer's test - To the $1 \mathrm{ml}$ of extract $1 \mathrm{ml}$ of Mayer's reagent (Potassium bismuth iodide solution) was added. Whitish yellow or cream coloured precipitate indicates the presence of alkaloids.

vii) Phenolic compounds

To the each plant extract $5 \% \mathrm{FeCl}_{3}$ solution was added. Deep blue-black colour indicates the presence of phenolic compounds.

\section{RESULTS AND DISCUSSION}

\section{Phenetic Variation}

Variations of glandular and non glandular trichomes with respect to the shape, length and number of cells were observed in the leaves of Piper species (Figure 01). Secretory cells were present in cross sections of leaves and stems. Non glandular trichomes were not observed in $P$. betle, $P$. walkeri and $P$. nigrum but they were observed in wild pepper species like $P$. sylsestre and $P$. zeylanicum. Glandular trichomes were observed in all the species.

It is reported that there is a great variability in the secretory materials of glandular trichomes such as polysaccharides, salts, lipids, essential oils, resin, proteins. Some plant leaf hairs have considerable flavonoid content (Werker, 2000). Therefore the present findings would be useful in evaluating defensive mechanisms of these plants.

The distinguishing feature of pepper stem anatomy (Figure 02) is the distribution of vascular bundles. There are two rings of vascular bundles- outer and inner rings. There are secretory cells lining the mucilage canal. This is the typical anatomy of stem of Piperaceae (Ravindran et al., 2000).

According to the phenogram (Figure 03) the taxa were divided in to two main clusters. 
The two $P$. longum varieties, $P$. zeylanicum, $P$. sylvestre, $P$. nigrum and $P$. walkeri form one main cluster while $P$. chuvya, $P$. betle varieties and $P$. siriboa form the second cluster. P. nigrum and $P$. walkeri show close similarities. Maneru and Ratadalu show close relationships while Nagawalli separated from them. P. chuvya and $P$. siriboa form separate clades in the second cluster.

According to the PCA (Figure 04) the first principal component (eigenvalue $=5.48092$ ) was mainly influenced by leaf width $(\mathrm{C})$ and leaf area $(\mathrm{J})$ and leaf length $(\mathrm{B})$. The second principal component (eigenvalue $=2.50088$ ) was mainly influenced by shape of the leaf base
(G), presence of fleshy spadix with concrescent berries (M), presence of stomata on adaxial epidermis (L). Leaf area and leaf width has similar correlations. The first two principal components explain $61.4 \%$ of the total variance.

Glandular trichomes were observed in all the taxa while non glandular multicellular trichomes were observed only in $P$. zeylanicum and $P$. sylvestre. Fleshy spadices with concrescent berries were formed by $P$. longum, $P$. betle, $P$. siriboa and $P$. chuvya. $P$. walkeri showed close similarities with $P$. nigrum. Nagawalli has more similar characters with other betel varieties, but with a yellow patch on its green leaves.
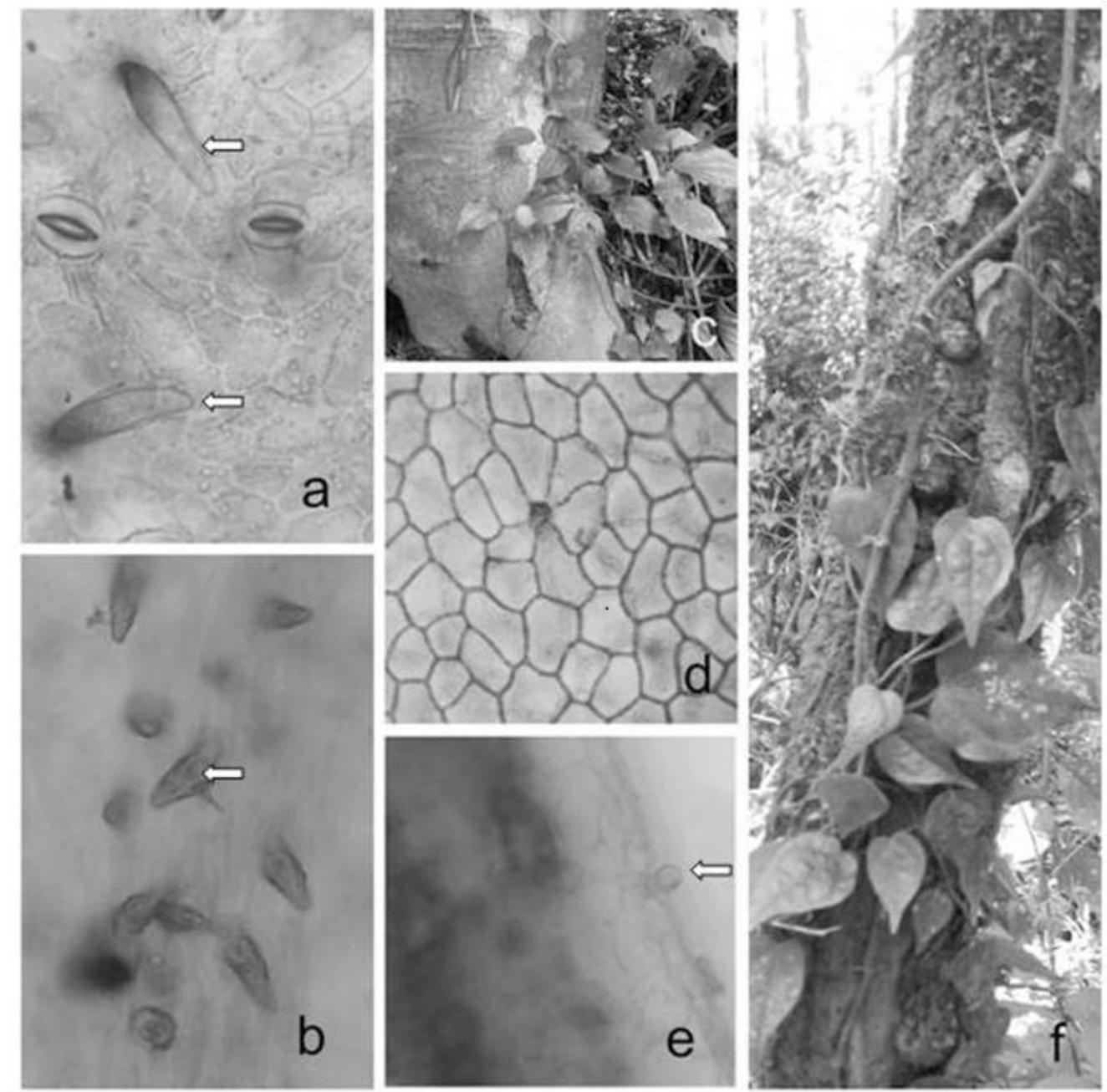

Figure 01: a. Abaxial epidermis of $P$. chuvya showing trichomes $(10 \times 40)$; b. abaxial epidermis of $P$. longum showing trichomes on veins $(10 \times 40)$; c. habit of $P$. sylvestre; d. adaxial epidermis of $P$. betle $(10 \times 40)$; e. cross section of $P$. betle leaf showing a pearl gland $(10 \times 40)$; $\mathrm{f}$. Habit of $P$. zeylanicum. 


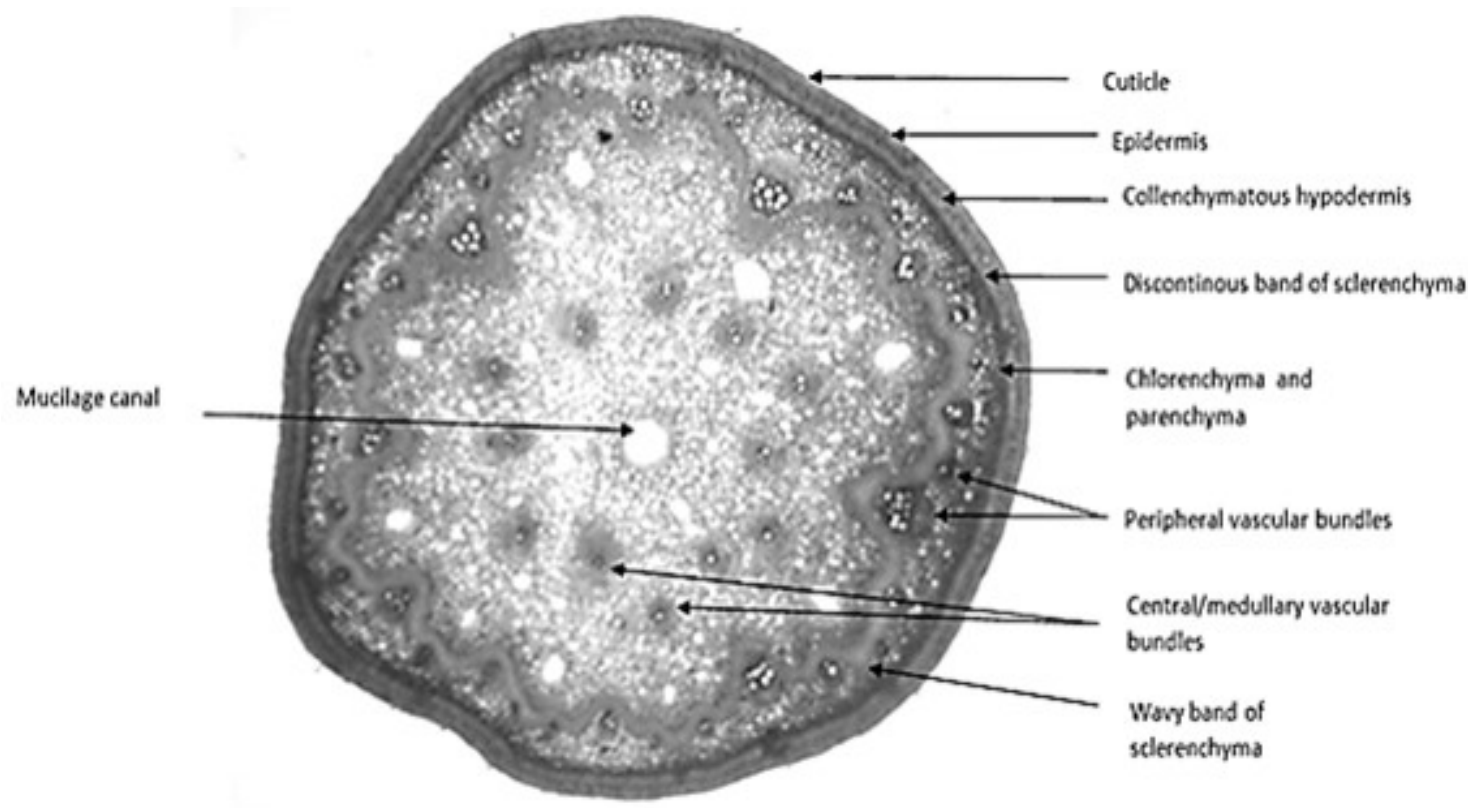

Figure 02: Cross section of P. nigrum stem $(10 \times 4)$ stained with toluidine blue

\begin{tabular}{|c|c|c|c|c|c|c|c|c|c|c|}
\hline & \multicolumn{9}{|c|}{ Distance } & \\
\hline$\omega$ & $\stackrel{N}{\sim}$ & $\mathrm{N}$ & $\stackrel{N}{\vec{u}}$ & $\vec{\phi}$ & $\overrightarrow{i r}$ & $\vec{i}$ & : & 웅 & i & $\circ$ \\
\hline
\end{tabular}

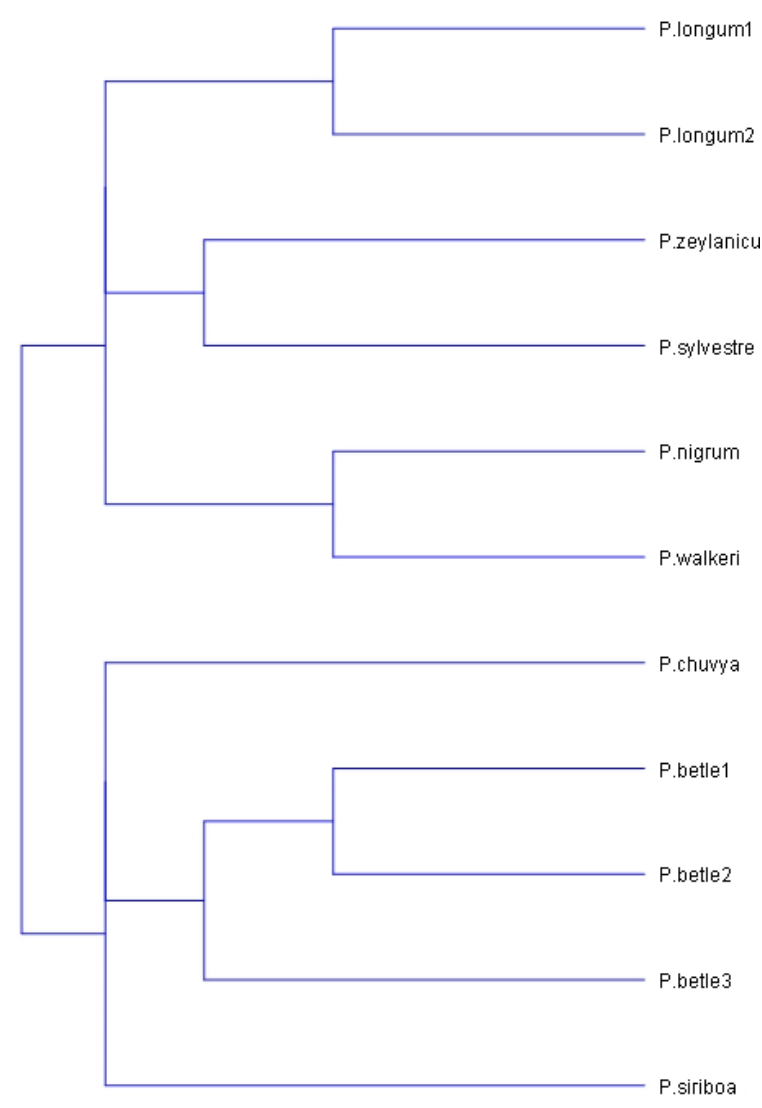

Figure 03: Clustering of Piper species by Single linkage, Euclidean distance.

(Note: $P$. betle 1 = Maneru, P. betle 2 = Ratadalu, $P$. betle 3 =Nagawalli) 


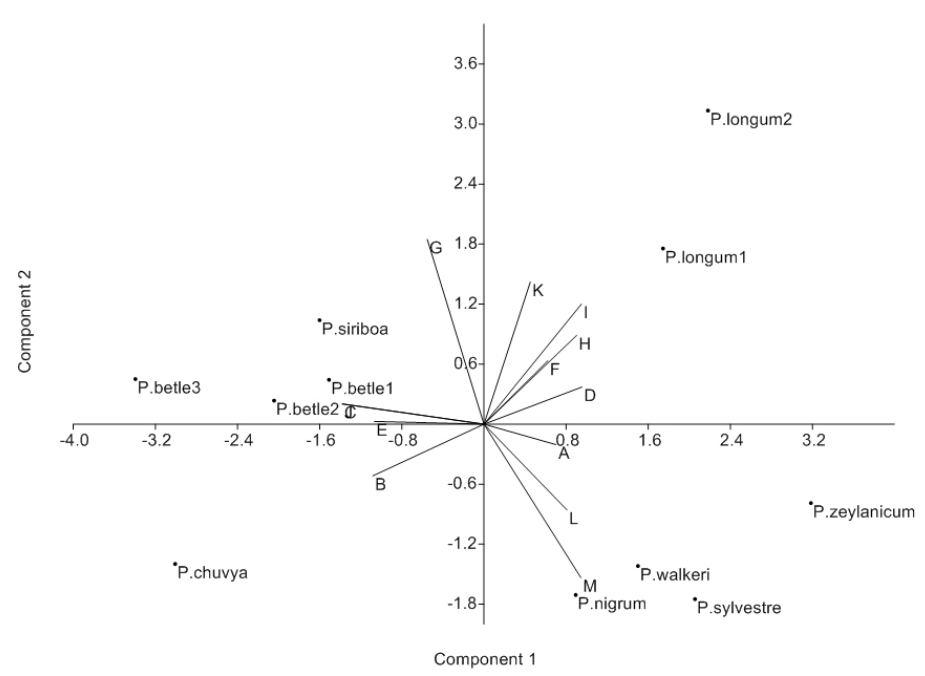

Figure 04: PCA biplot; characters are symbolized by capital letters and described in Table 02

\section{Qualitative Phytochemical Screening}

Aqueous extract of the leaves confirmed the presence of tannins, flavonoids, terpenoids, glycosides and phenolics while alkaloids and saponins were not detected in the studied samples.

The phytochemical screening (Table 03) indicated the presence of tannins, flavonoids, terpenoids, glycosides, alkaloids and phenolic compounds in Piper spp. whereas saponins were not detected in this study. Most of the phytochemicals were extracted into methanol.
Besides the two crop plants (P. betle and $P$. nigrum) other species also revealed their similarities with respect to the phytochemicals which indicate the potential of utilizing these species in crop improvement programs. Piperine which is an alkaloid, is the principal compound responsible for pungency in black pepper. Similarly alkaloids were detected from the wild species suggesting the potential of the use of those in future crop improvement programmes. Hence, further studies are needed to quantify these phytochemicals to disclose the interspecific variation of the species.

Table 03: Qualitative phytochemical analysis of leaf extracts of Piper spp.

\begin{tabular}{|c|c|c|c|c|c|c|c|c|c|c|c|c|c|c|c|c|c|c|c|c|c|c|c|c|c|c|c|c|c|c|c|c|}
\hline \multirow{3}{*}{$\begin{array}{l}\text { Class of } \\
\text { compounds }\end{array}$} & \multicolumn{32}{|c|}{ Species } \\
\hline & \multicolumn{4}{|c|}{ P. sylvestre } & \multicolumn{4}{|c|}{ P. siriboa } & \multicolumn{4}{|c|}{ P. chuvya } & \multicolumn{4}{|c|}{ P. longum } & \multicolumn{4}{|c|}{$P$. nigrum } & \multicolumn{4}{|c|}{ P. betle } & \multicolumn{4}{|c|}{ P. zeylanicum } & \multicolumn{4}{|c|}{ P. walkeri } \\
\hline & $\mathrm{P}$ & $\mathrm{C}$ & $\mathrm{E}$ & M & $\mathrm{P}$ & $\mathrm{C}$ & $\mathrm{E}$ & M & $\mathrm{P}$ & $\mathrm{C}$ & $\mathrm{E}$ & $\mathrm{M}$ & P & $\mathrm{C}$ & $\mathrm{E}$ & M & $\mathrm{P}$ & $\mathrm{C}$ & $\mathrm{E}$ & M & $\mathrm{P}$ & $\mathrm{C}$ & $\mathrm{E}$ & $\mathrm{M}$ & $\mathrm{P}$ & $\mathrm{C}$ & $\mathrm{E}$ & $\mathrm{M}$ & $\mathrm{P}$ & $\mathrm{C}$ & $\mathrm{E}$ & M \\
\hline Tannins & - & - & - & + & - & - & + & + & - & - & - & + & - & - & - & + & - & - & - & + & - & - & + & + & - & - & - & + & - & - & - & + \\
\hline Flavonoids & - & - & - & + & - & - & - & + & - & - & - & + & - & - & - & + & - & - & - & + & - & - & - & + & - & - & - & + & - & - & - & + \\
\hline Terpenoids & + & + & + & + & + & + & + & + & - & + & + & + & + & + & + & + & + & + & + & + & + & + & + & + & + & + & + & + & + & + & + & + \\
\hline Glycosides & - & - & + & + & - & + & + & + & - & - & + & + & - & - & + & + & - & + & + & + & - & + & + & + & - & + & + & + & + & + & + & + \\
\hline Alkaloids & - & - & - & + & - & - & - & + & - & - & - & + & - & - & - & + & - & - & - & + & - & - & - & + & - & - & - & + & - & - & - & + \\
\hline Phenolic & - & - & - & + & - & - & + & + & - & - & - & + & - & - & - & + & - & - & - & + & - & - & + & + & - & - & - & + & - & - & - & + \\
\hline \multicolumn{33}{|l|}{ compounds } \\
\hline Saponins & - & - & - & - & - & - & - & - & - & - & - & - & - & - & - & - & - & - & - & - & - & - & - & - & - & - & - & - & - & - & - & - \\
\hline
\end{tabular}

[Note: P- petroleum ether, C- chloroform, E- ethyl acetate, M- methanol, $(+)$ indicates presence, $(-)$ indicates not detected] 
Piper betle and $P$. nigrum are the main crop plants in this genus which suffer from various diseases. Bacterial leaf blight is one such disease which causes serious damages to the betel cultivation and there are no effective control measures other than the destruction of the diseased plants (Department of Export Agriculture, 2015). Wild relatives of these crop plants may rich with useful chemicals and, anatomical and morphological features that would aid to thrive in natural habitats with various abiotic stresses and pathogen and pest attacks. Therefore it is necessary to pay attention on crop wild relatives as they contain valuable traits that are beneficial for crop improvement programs.

\section{CONCLUSIONS}

The cluster analysis indicated close similarities between two P. longum varieties, P. zeylanicum and $P$. sylvestre, $P$. nigrum and $P$. walkeri while forming a main cluster. $P$. betle varieties were clustered together and showed close relationships with $P$. siriboa and $P$. chuvya within the second cluster. Hence betel cultivars are susceptible to diseases and has reported to develop epidemics in several cultivations which has caused economic losses to growers and to the economy of the country. Both P. siriboa and P. chuvya are found in wild hence their potential strengths of resistance can be used by plant breeders to develop improved betel varieties. Preliminary phytochemical screening revealed the presence of tannins, flavonoids, terpenoids, glycosides, alkaloids and phenolic compounds in all taxa.

\section{REFERENCES}

Bourgaud F, Gravot A, Milesi S, Gontier E. (2001) Production of plant secondary metabolites: a historical perspective. Plant Science; 161(5): pp 839-851. http://dx.doi.org/10.1016/S01689452(01)00490-3

Carpenter, K.J. (2006). Specialized structures in the leaf epidermis of basal Angiosperms: morphology, distribution, and homology. American Journal of Botany, 93: pp 665-681. http://dx.doi.org/10.3732/ajb.93.5.665

Chakraborty. D. and Shah, B. (2011). Antimicrobial, antioxidative and antihemolytic Activity of Piper betel leaf extracts, International Journal of Pharmacy and Pharmaceutical Sciences, 3(3): pp 192-199.

Department of Agriculture, Government of Sri Lanka, (2006). Crop Wild Relatives. http://www. agridept.gov.lk/index.php/en/crop-wild-relatives/1126. 20.07.2015.

Department of Export Agriculture, Sri Lanka, (2015). Betel: Crop protection. http://www. exportagridept.gov.lk/web/index.php?option=com_content\&view=article\&id=126\&Itemid $=159 \&$ lang=en. 20.07.2015.

Edirisinghe, R.W. (2009). Observation on Piper hymenophyllum Miq. : A rare wild Piper species in Sri Lanka. Ceylon Journal of Science (Biological Sciences), 38(1): pp 23-26. http://dx.doi. org/10.4038/cjsbs.v38i1.1324 
Harborne, J.B. (1998). Phytochemical methods. A guide to modern techniques of plant analysis. $3^{\text {rd }}$ ed., Chapman and Hall Int. Ed., New York. pp 1-131.

Huber, H. (1987). Piperaceae. Dassanayake, M.D. and Fosberg, F.R. (Eds.). A revised Handbook to the Flora of Ceylon. Ameirnd Publishing Private Limited, New Delhi, India. pp 273-289.

Khandelwal, K.R. (2008). Practical Pharmacognosy, $19^{\text {th }}$ Edition. Nirali Prakashan, Pune. pp 149160.

Liyanage, A.S.U. and Senanyake, G. (2010). The Atlas of Selected Crop Wild Relatives in Sri Lanka, Peradeniya: Department of Agriculture, Sri Lanka.

Parthasarathy, U., Saji, K.V., Jayarajan, K. and Parthasarathy, V.A. (2006). Biodiversity of Piper in South India - application of GIS and cluster analysis, Current Science, 91(5), pp 652-658.

Ravindran, P.N., Babu, K.N., Sasikumar, B. and Krishnamurthy, K.S. (2000) Botany and Crop Improvement of Black Pepper. In: Black Pepper (Piper nigrum). (Ravindran, P.N., Eds.). Harwood Academic Publishers, Amsterdam, Netherlands. pp 23-142.

Senaratna, L. K. (2001). A Check List of the Flowering Plants of Sri Lanka. National Science Foundation, Colombo, Sri Lanka. pp 263-264.

Shun, C.Y., Chau, J.W., Jing, J.L., Pei, L.P., Jui, L.H. and Fen, P.C. (2007). Protection effect of Piper betle leaf extract against carbon tetrachloride induced liver fibrosis in rats. Archives of Toxicology, 81, pp 45-55. http://dx.doi.org/10.1007/s00204-006-0106-0

Wadt, L.H.O., Ehringhaus, C. and Kageyama, P.Y. (2004). Genetic diversity of "Pimenta longa" genotypes (Piper spp., Piperaceae) of the Embrapa Acre germplasm collection. Genetics and Molecular Biology, 27(1): pp 74-82. http://dx.doi.org/10.1590/S1415-47572004000100013

Werker, E. (2000). Trichome Diversity and Development. In Advances in Botanical research incorporating Advances in Plant Pathology-Plant Trichomes (Hallahan, D.L., Gray, J.C. and Callow, J.A. Eds.). Academic Press, London. pp 1-30. http://dx.doi.org/10.1016/s00652296(00)31005-9 